\title{
What if the Fed Had Been an Inflation Nutter?
}

\author{
Paul Söderlind* \\ Stockholm School of Economics
}

April 19, 2001

\begin{abstract}
A structural rational expectations model of U.S. monetary policy is used to make a counterfactual experiment of a strongly inflation averse Federal Reserve Bank. Results for U.S. interest rates, output, and inflation over 1965-1999 are discussed.
\end{abstract}

Keywords: Optimal monetary policy, rational expectations, Kalman filter.

JEL Classification Numbers: E31, E43, E52.

* Stockholm School of Economics and CEPR. Address: Stockholm School of Economics, PO Box 6501, SE-113 83 Stockholm, Sweden. E-mail: Paul.Soderlind@hhs.se. 


\section{Introduction}

This paper studies how U.S. output, inflation, and interest rates would have evolved 19651999 if the Federal Reserve Bank had been more inflation averse. This counterfactual experiment is done with a structural rational expectations macro model.

Similar types of counterfactual experiments are discussed in several other papers, for instance, Clarida, Galí, and Gertler (1998), Rotemberg and Woodford (1999), and Bergvall (2000). These experiments can tell us a great deal about how monetary policyand our models of monetary policy-works.

The approach I take here has several advantages, however. First, the notion of a more inflation averse central bank is parameterized in terms of the bank's objective function rather than in terms of a decision rule. Second, results from the experiments are shown for output and inflation (requires solving for the new rational expectations equilibrium), not just the policy instruments. Third, the results for the actual paths of output and inflation are shown, not just the implied unconditional variances. Fourth, the model parameters are estimated (with maximum likelihood) on historical data, rather than just calibrated. Some papers share one or a few of these advantages, but rarely all four.

\section{A Model of Monetary Policy}

To perform the policy experiment, I use a version of the model in Fuhrer and Moore (1995) (the wage contracts are one period shorter, but policy optimizes an objective function). The IS curve for detrended log output, $y_{t}$, is

$$
y_{t}=\alpha_{1} y_{t-1}+\alpha_{2} y_{t-2}+\alpha_{r} r_{t-1}+\varepsilon_{y t},
$$

where $\varepsilon_{y t}$ is an output shock. The long ex ante real interest rate, $r_{t}$, obeys an approximate risk neutral arbitrage condition for a ten year real coupon bond

$$
r_{t}=\sum_{s=0}^{\infty}(40 / 41)^{s} \mathrm{E}_{t}\left(i_{t+s}-\pi_{t+1+s}\right) / 41,
$$

where $i_{t}$ is the annualized one quarter nominal interest rate, and $\pi_{t}$ the annualized one quarter inflation rate, $\pi_{t}=4\left(p_{t}-p_{t-1}\right)$.

Wage contracts negotiated in $t$ specify a flat nominal wage, $w_{t}$, for three quarters, but not all contracts "survive" until $t+1$ or $t+2$. As a consequence, the fraction $\theta_{0}$ of existing 
(in $t$ ) contracts were written in $t$, the fraction $\theta_{1}$ in $t-1$, and the rest in $t-2$. The $\log$ price level is the average of these wage contracts

$$
p_{t}=\theta_{0} w_{t}+\theta_{1} w_{t-1}+\left(1-\theta_{0}-\theta_{1}\right) w_{t-2} .
$$

Nominal wage contracts are set so the current real contract wage, $w_{t}-p_{t}$, equals the expected value of the wage contracts written during the next two periods-adjusted for demand pressure and negative supply shocks, $\varepsilon_{p t}$,

$$
\begin{aligned}
w_{t}-p_{t} & =\theta_{0}\left(v_{t}+\gamma y_{t}\right)+\theta_{1} \mathrm{E}_{t}\left(v_{t+1}+\gamma y_{t+1}\right)+\left(1-\theta_{0}-\theta_{1}\right) \mathrm{E}_{t}\left(v_{t+2}+\gamma y_{t+2}\right)+\varepsilon_{p t}, \\
v_{t} & =\theta_{0}\left(w_{t}-p_{t}\right)+\theta_{1}\left(w_{t-1}-p_{t-1}\right)+\left(1-\theta_{0}-\theta_{1}\right)\left(w_{t-2}-p_{t-2}\right) .
\end{aligned}
$$

The Fed sets the short nominal interest rate. The wage contracting schedule makes inflation expectations somewhat sticky, so the Fed can influence the ex ante real interest rate and therefore output. This has an affect on inflation via the Phillips effect. The Fed is assumed to commit to a policy rule which strikes a balance between output, inflation, and interest rates volatility; the loss function is

$$
L_{t}=\mathrm{E}_{t} \sum_{s=t}^{\infty} \beta^{s-t}\left[q_{y} y_{s}^{2}+\left(1-q_{y}\right) \pi_{s}^{2}+q_{i} i_{s}^{2}\right]
$$

\section{Estimation and a Policy Experiment}

The model is estimated in Söderlind (2001) with the maximum likelihood method. A guess of the parameter vector is used in a solution algorithm for rational expectations models. This gives an optimal policy rule and a system of linear difference equations for the model variables, which can be used in a Kalman filter to build up the likelihood function of the data. The estimation algorithm iterates over the parameters to find the vector that maximizes the likelihood function. (See Söderlind (1999) for a summary of recent methods for solving and estimating rational expectations models of monetary policy.)

The sample is quarterly U.S. data for 1966Q1 to 1995Q4 where $y_{t}$ is taken to be log real GNP per capita detrended with a linear trend, $\pi_{t}$ is the annualized quarterly change in the consumer price index for urban workers, and $i_{t}$ is the three month T-bill rate plus an error term (which can be interpreted as a policy shock). The three shocks (demand shock, 
supply shock, and the interest rate shock) are assumed to be iid normally distributed. ${ }^{1}$ The means are subtracted from all variables before estimation since the model variables have zero means.

Once the model is estimated, a Kalman smoothing algorithm (Harvey (1989)) is used to make the best possible estimate of the shocks that hit the U.S. economy over the period 1965-1999, and also of the initial state of the economy in 1965Q1. This state needs to be estimated since only parts of it are directly observable, for instance lagged output, while other parts are not directly observable, for instance, lagged wage contracts and lagged ex ante real interest rates.

The estimated shocks have several reassuring features. First, the inflation peaks in mid and late 1970s are estimated to come from negative supply shocks. Second, the Volcker deflation is not attributed to the supply or demand shocks, but to systematic monetary policy and interest rate shocks. Third, the early 1990s shows negative demand shocks, and the late 1990s is characterized by both positive demand and supply shocks.

The counterfactual experiment of a more inflation averse Fed is done by changing the weight on output stability in the loss function, $q_{y}$, from the estimated 0.82 to 0.1 and the weight on interest rate stabilization, $q_{f}$, from the estimated 0.35 to 0.1 . This means that the Fed focuses much more on inflation stability, even if it comes at the expense more volatility in output and interest rates. This particular policy experiment is only meant to capture the idea of a more inflation averse Fed than observed (estimated) from historical data, but it generates changes in the standard deviations of output, inflation, and interest rates which are in line with other studies. I solve for the dynamic rational expectations equilibrium with these new parameters, and simulate the economy by starting from the estimated state of the economy in 1965Q1 and feeding in the estimated shocks.

One effect of an inflation averse policy is to decrease the standard deviation of inflation 1965-1999 by around 25\%. The estimated Phillips effect is not particularly strong (something which is also found in several other studies, for instance, Roberts (1995)), so decreased inflation volatility comes at the cost of a $40 \%$ increase in the standard deviation of detrended output (and a and 65\% increase in the standard deviation of the interest rate).

The actual and simulated macro series are shown in Figure 1. Figure 1a shows, among other things, that an inflation averse Fed would have been more persistent and force-

\footnotetext{
${ }^{1}$ The estimation results are the following: in the IS curve $\left(\alpha_{1}, \alpha_{2}, \alpha_{r}, \operatorname{Std}\left(\varepsilon_{y t}\right)\right)=(1.39,-0.50$,$0.55,0.84)$; in the loss function $\left(q_{y}, q_{i}\right)=(0.82,0.35)$; in the price equations $\left(\theta_{0}, \theta_{1}, \gamma, \operatorname{Std}\left(\varepsilon_{p t}\right)\right)=$ $(0.62,0.29,0.0019,0.19)$; and the T-bill Std error is 1.41 .
} 
a. Interest rate

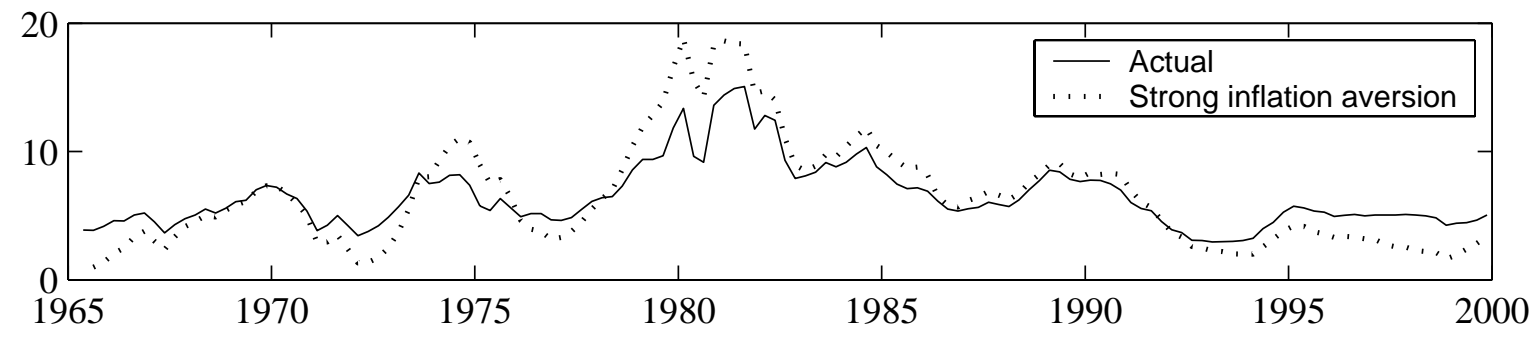

b. Output

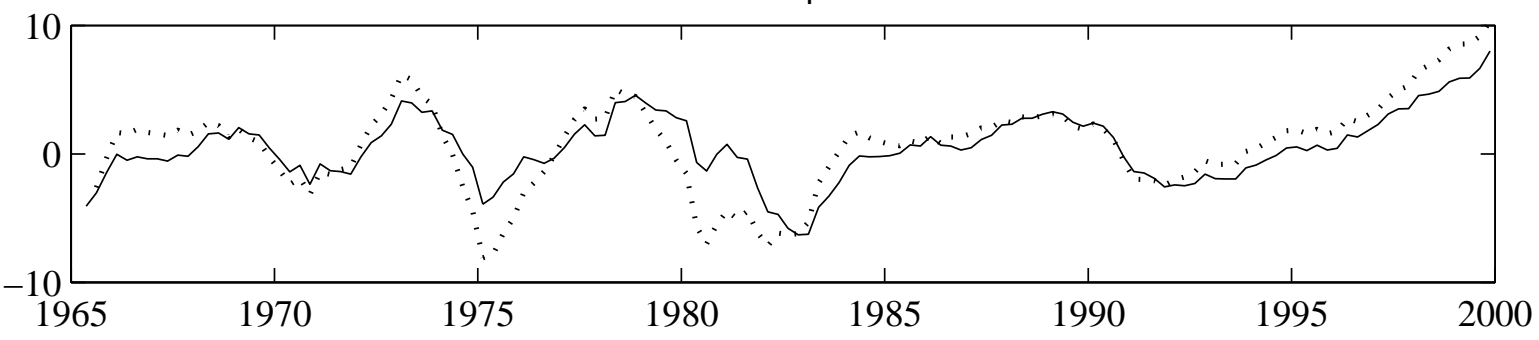

c. Inflation

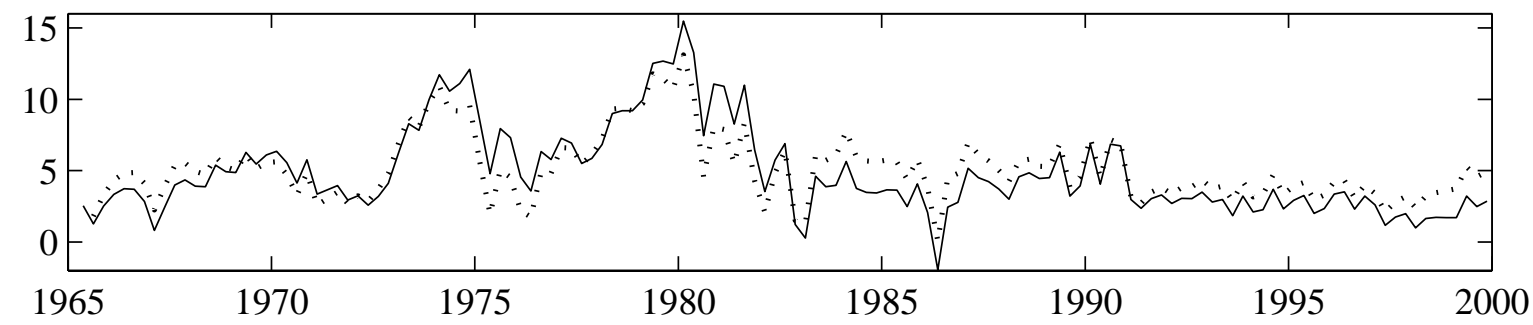

Figure 1: Actual and simulated U.S. interest rates, output, and inflation. The interest rate is the three-month T-bill rate; output is log real GNP per capita detrended with a linear trend; inflation is the annualized quarterly change in the consumer price index for urban workers.

ful (3.5\% higher interest rate) in fighting inflation after the first oil price shock, reacted quicker and more (6\% higher interest rate) to the second oil price shock, and pursued a looser monetary policy during the second half of the 1990s when inflation was low.

The cost of this policy shows up in Figure $1 \mathrm{~b}$ as long and large recessions around the oil price shocks. In particular, most of the first half of the 1980s would have been a deep recession. On the other hand, the looser monetary policy in the late 1990s would have boosted the economy further.

These movements in output would have helped keeping inflation under control, even if inflation fighting gives little immediate payoff. Figure 1c shows that inflation in 1973 
and early 1974 would not have been lower than in data, but inflation in 1975-1976 would have been some 3\% lower. Similarly, inflation in 1979 would not have been much lower than in data, but in 1980-1981 it would again have been around 3\% lower.

There are two reasons for this result. First, the inflation inertia, built into the model as overlapping wage contracts, means that part of today's inflation is due to contracts written in earlier periods: the inflation response to a monetary policy is sluggish. Second, the Phillips effect is not very strong, so it would take a really deep recession to counter the strong inflation impulses of the oil price shocks. The policy maker in this model has a quadratic loss function and is therefore more willing to create a mild but long recession than a very deep but short depression.

Should we believe these arguments? The degree of inflation inertia and fairly weak Phillips effect are estimated from historical data, and similar results are found in many other studies, so that part of the argument is probably robust. However, the degree of convexity of the loss function is not estimated: the quadratic form was assumed a priori. Although this form is very popular in theoretical work (mostly for reasons of convenience) and has some intuitive appeal, it remains an open issue if it is a good approximation of policy makers preferences.

\section{References}

Bergvall, A., 2000, "Exchange Rate Regimes and Macroeconomic Stability: The Case of Sweden 1972-1996," Working Paper 2000:25, Department of Economics, Uppsala University.

Clarida, R., J. Galí, and M. Gertler, 1998, "Monetary Policy Rules in Practice: Some International Evidence," European Economic Review, 42, 1033-1067.

Fuhrer, J. C., and G. Moore, 1995, "Monetary Policy Trade-Offs and the Correlation Between Nominal Interest Rates and Real Output," American Economic Review, 85, 219-239.

Harvey, A. C., 1989, Forecasting, Structural Time Series Models and the Kalman Filter, Cambridge University Press, Cambridge. 
Roberts, J. M., 1995, "New Keynasian Economics and the Phillips Curve," Journal of Money, Credit, and Banking, 27, 975-984.

Rotemberg, J. J., and M. Woodford, 1999, "Interest Rules in an Estimated Sticky-Price Model," in J. B. Taylor (ed.), Monetary Policy Rules, University of Chicago Press.

Söderlind, P., 1999, "Solution and Estimation of RE Macromodels with Optimal Policy," European Economic Review, 43, 813-823.

Söderlind, P., 2001, "Monetary Policy and the Fisher Effect," Journal of Policy Modeling, Forthcoming. 